\title{
New opportunities for the development of smart cities in Italy: the role of banking foundations
}

\section{Chiara Crovini* ${ }^{*}$ Giovanni Ossola and Guido Giovando}

Department of Management,

School of Management and Economics,

University of Turin,

C.so Unione Sovietica 218/bis, 10134, Turin, Italy

Email: chiara.crovini@unito.it

Email: giovanni.ossola@unito.it

Email: guido.giovando@unito.it

*Corresponding author

\begin{abstract}
The present study represents a theoretical contribution in the field of smart cities and banking foundations and, in particular, the paper aims to underline the opportunities and the potential benefits of banking foundations supporting the development of smart cities in Italy. We analysed the reports on strategic business plan of the period between 2017-2019, published by the eighty-eight banking foundations, the corporate governance and the internal organisation model, the notes to the financial statements and the websites of the Italian banking foundations and, through a deductive approach, we elaborated their general business model. This research, thanks to its multidisciplinary approach, contributes to the body of knowledge by providing a virtuous example of interactions and synergies between smart cities and banking foundations in Italy. This work represents the first step of a far deeper analysis and consequently future developments will constitute valid tests of core arguments deeply analysed in this context.
\end{abstract}

Keywords: smart cities; smart sustainable cities; Italian banking foundations; business model; innovation.

Reference to this paper should be made as follows: Crovini, C., Ossola, G. and Giovando, G. (2019) 'New opportunities for the development of smart cities in Italy: the role of banking foundations', World Review of Entrepreneurship, Management and Sustainable Development, Vol. 15, No. 3, pp.393-408.

Biographical notes: Chiara Crovini received her $\mathrm{PhD}$ in Business and Management at the Department of Management, University of Turin, Italy. Her research area covers all the topics related to risk management, corporate governance, internal control systems, internal auditing, statutory audit of SMEs, banks and credit institutions. She is a member of Accademia Italiana di Economia Aziendale Giovani (AIDEA Giovani), SIDREA (Società Italiana dei Docenti di Ragioneria e Economia Aziendale), International Academy of Business and Economics, B.S. - Lab. (Business Systems Laboratory) and ERRN (European Risk Research Network). She is a reviewer of Global Business and Economics Review and World Review of Entrepreneurship, Management and Sustainable Development, Inderscience Publisher. She is a chartered accountant and statutory auditor. 
Giovanni Ossola is a Full Professor in Business Administration at the Department of Management, University of Turin, Italy. Currently, he is teaching business administration in the Bachelor degree courses and financial accounting and financial statements of banks and credit institutions in the Master degree courses. He is a chartered accountant and statutory auditor in many companies. $\mathrm{He}$ is a Member of Accademia Italiana di Economia Aziendale (AIDEA). $\mathrm{He}$ is the author of many national and international publications in the banking and assurance field, financial accounting and airport infrastructure.

Guido Giovando is an Associate Professor in Business Administration at the Department of Management, University of Turin, Italy. Currently, he is teaching business administration and cost accounting in the Bachelor degree courses and accounting and financial statements of banks and credit institutions in the Master degree courses. He is a chartered accountant and statutory auditor in many companies. He is the author of many national and international publications in the banking and assurance field, financial accounting and airport infrastructure. $\mathrm{He}$ is an Associate EuroMed Academy of Business (EMAB) Fellow of the EuroMed Academy of Business (EMAB).

\section{Introduction}

Smart cities play a key role in involving sustainable open and user-driven innovation ecosystems to improve firms' innovativeness and enhance the quality of life (Schaffers et al., 2011). However, to allow cities to share data across systems and to coordinate processes across domains, it is essential to break some existing barriers within and across public and private organisations within the city's innovation ecosystem (Carayannis and Campbell, 2009).

From the firm perspective, it is essential to exploit these positive synergies to innovate the business model, to create value over the long period (Scuotto et al., 2016) and to rethink and to adapt the business process management both inside and outside the firm (Del Giudice, 2016). To do this, private managers need to carefully collaborate with other stakeholders within the ecosystem, mainly with public governments, leading to some criticisms, which is typical of public-private partnerships (PPP) (Sandulli et al., 2016).

Approximately ten years ago, the Centre of Regional Science in Wien elaborated the Ranking of European medium-sized cities. This project dealt with medium-sized smart cities and their perspectives for future developments.

The challenges of those cities, which can be rather different, remain unexplored to a certain degree. Medium-sized cities, which must cope with competition of the larger metropolises on corresponding issues, appear to be less well equipped in terms of critical mass, resources and organising capacity. To enforce an endogenous development and achieve a good position, even these cities should aim at identifying their strengths and chances for positioning and ensure and extend comparative advantages in certain key resources against other cities of the same level. A forward-looking development approach should consider issues such as awareness, flexibility, transformability, synergy, individuality, self-decisive and strategic behaviour. Especially awareness is important for a smart city because certain potentials can only be exploited if inhabitants, companies or 
the public administration are aware of the cities' position. Knowing the city from the inside but also being aware of the surroundings and the system in which the city is in are important factors.

It is in this precise position and role that Italian banking foundations intervene in supporting Italian smart cities.

The banking foundations are legal entities of private law, non-profit making and independent, which pursue exclusively aims that are socially beneficial and support the territory to which they refer (Legislative Decree no. 153/99, Monge, 2016). These institutions pursue the final objective of satisfying the needs expressed by the members of the local community (Cioccarelli and Previtali, 2002).

There are no previous studies, considering the active role, also in terms of economic and financial support, of such foundations for the development and transformation of Italian cities into smart and sustainable cities.

This research, thanks to its multidisciplinary approach, contributes to the body of knowledge by providing a virtuous example of interactions between smart cities and banking foundations in Italy.

Interactions that clearly emerge in the general business model of such institutions, elaborated after analysing the reports on strategic business plans, referred to the period between 2017/2019 and published by the eighty-eight Italian foundations, the notes to the financial statements, referring to 2015 , and the corporate governance and internal organisation model.

This work represents the first step of a far deeper analysis and consequently subsequent research will constitute valid tests of core arguments deeply analysed in this context.

The paper is organised as follows: in Paragraph 2 we provide the Literature Review on the topic of smart and smart sustainable cities and Italian banking foundations; the research design is presented in Section 3; in Paragraph 4 we discuss the generalised business model of those foundations and finally we drive our conclusions.

\section{Literature review}

\subsection{Smart cities and smart sustainable cities}

The term 'smart city' is extremely difficult to define. Bibri and Krogstie (2016) states that a smart city is the idea that various urban systems and domains become interconnected through ICT for their better efficiency, management, and planning. More specifically, smart cities combined with urban innovation and ICT aim at harnessing physical and social infrastructures as well as natural and knowledge resources for environmental and economic regeneration and enhanced public and social services (Ferraris and Santoro, 2014; Lazaroiu and Roscia, 2012). Smart city has many faces, which tend to vary based on how and in what ways ICT is applied (Sujata et al., 2016; Paroutis et al., 2014). The definition of smart city is also based on the area of focus (Navarro et al., 2017; Al Nuaimi et al., 2015). A description of smart city provided by Caragliu et al. (2009, p.6) is based on a model that has been used as a classification system, developed through six distinct dimensions, namely smart mobility, smart environment, smart living, smart people, smart economy, and smart governance, through which smart cities can be gauged or evaluated in terms of their development. Here, the 
concept of smart city can be seen as an urban development strategy to highlight the growing role of ICT infrastructure in catalysing and improving some dimensions of urban sustainability. Other definitions of smart city emphasise the pervasiveness of ICT, an aspect which characterises the prevalent ICT visions of the new wave of computing, as well as the integration of ICT with urban design and planning. Townsend (2013, p.15) defines a smart city as an urban environment where ICT 'is combined with infrastructure, architecture, everyday objects, and even our own bodies to address social, economic and environmental problems'. Piro et al. (2014, p.169) describe it 'as an urban environment which, supported by pervasive ICT systems, is able to offer advanced and innovative services to citizens to improve the overall quality of their life.

Toppeta (2010) underlines that a smart city attempts to amalgamate advanced digital technologies and urban planning approaches to find innovative solutions that contribute to improving the sense of living and enhancing sustainability.

In addition, smart initiatives can be used to promote environmental sustainability (Kramers et al., 2014; Kilili and Fokaides, 2015).

March (2016) states that smart cities encapsulate all the desires and prospects on the transformative and disruptive role technology will have in solving urban issues both in Global North and Global South cities. Critical scholarship has pointed out that private capital, with the blessing of technocratic elites, has found a techno-environmental fix to both reshuffle economic growth and prevent other alternative politico-ecological transitions to take root in urban systems. Against this idea, the paper argues that these technological assemblages might be compatible with alternative post-capitalist urban transformations aligned with Degrowth. Through a cross-reading of research on Smart Cities with theoretical perspectives drawn from the literature on Degrowth, March suggests that Degrowth should not refrain from engaging with urban technological imaginaries in a critical and selective way.

The topic of ICT is also connected to smart cities in the research of Zhuhadar et al. (2017), in which he studied the IBM Intelligent Operation Center (IOC) as a 'system of systems', which is intended to extract only the data necessary to optimise the operations of the organisation. The types of data and integration into the IOC make efficient problem solving solutions readily available to city authorities. The need for smart cities, universities, campuses, citizens, and students to drive growth of urban and regional economies is evident. In this article, a thorough analysis of the architectural design of an intelligent operational system is completed to present a smart solution for cities to unify departments and agencies under one umbrella.

Mattoni et al. (2015) underline that smart cities represent a balance among hardware and software aspects, technology and human capital, and they aim at realising and guaranteeing the quality of life to the inhabitants.

The aim of their paper is to outline a planning methodology of actions to realise a Smart City that provides a holistic and specific approach to territories and cities by taking into account the specific features of the context and by developing different and appropriate strategies. According to this, a new way to integrate the various aspects of a smart city through the definition of the relations existing among all the subsystems of the city, considered as a whole (human) organism, was developed.

Over the past few years, there has been growing attention to the concept of smart sustainable city, as a new techno-urban phenomenon (Höjer and Wangel, 2015; Al-Nasrawi et al., 2015; Rivera et al., 2015; Ferraris and Santoro, 2014). Smart sustainable cities derive from the interactions between social, urban, and technological 
elements, and, in particular, from the development of sustainability awareness, urban growth, and technological development (Höjer and Wangel, 2015). The concept has emerged on the basis of five different developments, that involve sustainable cities, smart cities, ICT, sustainable urban development, sustainability and environmental issues, and urbanisation and urban growth (Ahvenniemi et al., 2017; Höjer and Wangel, 2015; Lindhult et al., 2016). The term 'smart sustainable city' is used to denote a city that is supported by a pervasive presence and massive use of advanced ICT, which enables cities to become more sustainable and to provide citizens with a better quality of life. In more detail, it can be described as a social fabric made of a complex set of networks of relations between various synergistic clusters of entities that in taking a holistic and systemic approach, converge on using and applying smart technologies that enable to continuously create, employ, and disseminate solutions that help provide a fertile environment that is conducive to improving the contribution to the goals of sustainable development (Bibri and Krogsite, 2016; Sandulli et al., 2016; Bakici et al., 2013). The combination of smart cities and sustainable cities, of which many diverse definitions are available, has been less explored as well as conceptually difficult to delineate due to the multiplicity and diversity of the existing definitions.

\subsection{Banking foundations in Italy}

The creation of banking foundations (FOB - Fondazioni di Origine Bancaria) was one of the most interesting elements in the field of non-profit organisations in Italy. The approval of the Law Amato-Carli July 30, 1990, n. 218 triggered the reform process with the transformation of the banking public institutions (savings banks) in foundations. This privatisation process culminated with the recognition of the banking foundations as legal subjects of private law, non-profit making, but with exclusive social aims (Legislative Decree no. 153/99; Monge, 2016).

The Amato Law led to the separation of lending from philanthropic activities. The lending activities were spun off and given to Savings Banks and Monte Spa Banks, which were profit-making, private business, governed by the Civil Code and by the rules on banking and financial matters like the other banks. The social, cultural, civil and economic activities instead remained to foundations, which initially were also the major shareholders of the new-born banking companies: property that has been significantly reduced over the years to fall below the controlling stake for most of Foundations. These institutions reached their final characterisation from an institutional and legal point of view with Ciampi reform of 1998/1999, which led to the recognition of their private legal nature, conclusively clearly established by the Constitutional Court with the decisions number 300 and 301 in September 2003.

Therefore, this reform allowed the publicly-owned Italian banks (Banco di Napoli, Monte dei Paschi di Siena, Istituto Bancario San Paolo di Torino, Banco di Sicilia Banco di Sardegna, Banca Nazionale del Lavoro, Sicilcassa) to transform on the one hand into a limited company and on the other to create the foundations that have been transferred all the activities that were not related to the banking field.

The Amato-Carli Law, in article 2, allows banks to overcome the ban, deriving from Law Decree 375 of March 12, 1936 and Law 141 of March 7, 1938 to operate simultaneously as commercial enterprises and investment and allows participation in industrial and commercial enterprises. 
Since 1990 an intense debate has accompanied the growth of the banking foundations, with an accentuation of the institutional issues, regulatory, financial and tax (Barbetta, 2008; Crociata and Sacco, 2008; Bompani, 2000; Borzaga and Cafaggi, 1999).

The development of managerial skills and orientation towards innovation also requires a reflection on the economic and business issues (Cioccarelli and Previtali, 2002) and, in particular, to the structure of corporate governance (Bodega et al., 2009; Marcon et al., 2002). The foundation, in fact, is nothing more than a business and therefore an economic institution destined to last, for the satisfaction of human needs, that orders and is run continuously in coordination with the production, with a direct impact on the procurement and consumption of wealth (Zappa, 1956). The banking foundation, in particular, has pursued the last institutional goal of satisfying the needs expressed by the members of the local community and to this end sets up a coordinated and unified system of economic operations - in compliance with the principle of savings - will allow it to regain the conditions for its own survival over time, creating value, instead of consuming it (Borgonovi, 1993).

The issue of corporate governance, considered as the set of boards that direct, supervise and monitor the proper functioning of the foundation, is a delicate and critical step as in the banking foundations assumes particular aspects, not to be missed if you want to understand how to set up proper political strategies that are necessary to achieve corporate objectives.

A sound corporate governance and an adequate and effective internal control system are the basis for the definition of the medium/long term strategy and plans to implement. Without a strategic vision the medium-long term objectives cannot be defined and consequently achieved. To do this, however, foundations also need a good management.

The governance structure of banking foundations is characterised by the following elements (Airoldi, 1995):

- the actors, that directly or indirectly affect the course and outcome of the decisionmaking process, bearers of their own interests (stakeholders)

- the contributions that these actors make

- the reward that the same actors receive in relation to their participation in governance bodies

- the institutional tools that keep the several actors involved, connected and dynamically balanced.

Even though overseeing and administering a foundation involves the same difficulties that an entrepreneur faces in running its business and although these elements are common to all companies, it is necessary to consider them in the specific context, rather special.

Therefore, it follows that, although each banking foundation is an entity, considered as a system (Brusa et al., 2013; Bertini, 1990; Ferrero, 1968, 1987) with rather peculiar aspects and purposes, the governance structure is directly affected by the specific characteristics of these institutions. First, the banking foundations, as previously stated, are legal entities of private law, non-profit making, and independent, which pursue exclusively aims that are socially beneficial and support the territory to which they refer. Given their nature, in the Italian banking foundations there is no a residual claimant (Cioccarelli and Previtali, 2002), a person who enjoys the residual right on the patrimony. 
Consequently, compared to other companies, the banking foundations operate in the absence of shareholder and this means that stakeholders take on a significant weight from a strategic point of view (Bodega et al., 2009). These are the main reasons why the legislator has decided to intervene with primary sources regulations to foster a foundation governance to be consistent with the characteristics and purposes of such institutions.

The Legislative Decree no. 153/1999 clearly spells out the process for the identification of stakeholders, for the appointment of representatives in the governing bodies of the local community, for the definition of the roles of the institutional bodies and responsibility of managers in the management of the core business activities of the foundation.

To introduce the generalised business model, presented in Paragraph 5, it is necessary to provide a brief theoretical framework about the corporate governance theories of the banking foundations, because governance and internal control system represent the key elements for the survival and the efficiency of these foundations. Therefore, by understanding this frame, it will be easier to analyse their business model and understand the reasons why they represent an important institution for the development of smart cities.

Some scholars (Bodega et al., 2009) believe that the institutional framework of the theory of enterprise, elaborated by Masini (Zattoni, 2006; Airoldi, 1995; Masini, 1978) is the basis of the banking foundations governance model. According to this theory, an essential condition for the consolidation of the government balance is that no-marginal stakeholders perceive as protected their interest. Should this not happen, the latter would be discouraged to offer resources for the firm's survival. The main resource for banking foundations is the legitimacy of the stakeholders, which results in the survival of the same and, consequently, in the value creation for the institution. Legitimacy that is directly influenced by the effectiveness of the foundation communication process and the degree of information transparency inward and outward. According to Cerbioni and Boesso (2013), however, it is desirable to identify more diverse theoretical references to define the governance model of banking foundations, due to their intrinsic nature. First, by considering the expectations of social and local counterparts, it seems more appropriate to refer to the stakeholder theory. The stakeholder theory has seen its most widespread since the contribution of Freeman (1984), who decided to establish an ethics law where the interests of stakeholders is the final aim of the business, and where the behaviour that considers corporate social responsibility as an important element is not limited to the mere pursuit of profit, but this kind of behaviour is considered as a source of competitive advantage. In the specific case of the banking foundations, the agency theory (Fama and Jensen, 1983; Fama, 1980; Jensen and Meckling, 1976) cannot be applied as lacking the shareholder's figure, therefore there cannot be constituted a potential conflict between principal (shareholder) and agent (manager) and then we cannot talk about the exclusive pursuit of shareholders' interests.

Another theory that can adapt to the context of the banking foundations is the democratic theory, since these institutions are linked to locally 'concerted' models of power management and less inspired by the only company cost-effective manner. The theory was born in the 19th century with Tocqueville who argued that the government of businesses depended on the consensus obtained by the 'governed', defined today as stakeholders. Some scholars (Gomez and Korine, 2005) tried to apply to modern reality the hypothesis of Tocqueville and truly democratic procedures such as the emancipation, the separation of powers and the power of representation constitute the very essence of 
the governance structure of each company (Gomez and Jones, 2000). Cerbioni and Boesso (2013) then connect the resource dependency theory to the need for members of the governing bodies to have specific expertise in relation to the need to pursue institutional goals and not the interests of only one party. In this context, it is necessary to refer to the theory developed by Pfeffer and Salancik in 1978 because the banking foundations, in the classical systemic perspective view, before being understood in their behaviour, they must first be understood in their context. The resource dependency theory recognises the influence of external factors on the organisational behaviour of a company, although framed in its own context, and managers must take action to reduce the uncertainty and dependence on the reference (Ulrich and Barney, 1984). Finally, Cerbioni and Boesso glimpse stretches of stewardship theory activities. Donaldson and Davis (1991) have introduced an alternative approach to the agency theory, not accepting the fundamental assumptions. First of all, they do not consider the potential risk of opportunistic behaviour of corporate managers, who only want to be good 'stewards' (i.e., managers) of the company assets. This means that the agency problem linked to the need of monitoring and incentive for the managers does not arise. On the contrary the main theme concerns the need for a governance structure adapted to facilitate the government to formulate and implement plans to achieve the highest business performance. Therefore it is clear that there is no single generally accepted governance theory and applicable to banking foundations. Consequently, we must agree with the statement made by Carver (2007), who argues that no real governance theory has been already developed. Therefore as part of banking foundations, the development of a governance model that meets all the requirements would be considered not only as a tool of compliance and warranty (compliance model) but also as an open decision-making model to the contributions of the main bearers of territorial interests (stakeholder model); plural in its operating mode (democratic model); able to aggregate the most suitable profiles for the exercise of various activities of the foundation (co-optation model) and put them in practice to the same service (partnership model). The width of the traced functions in the exercise of the government seems to justify the legislation choice of a dual model where the policy-making Board takes charge of compliance principles, stakeholder representation and democratic exercise and the administrative board supervises the guarantee aspects, co-optation and partnership, not forgetting the need to have an internal control body exercising supervisory functions and accounting control.

\section{Research design}

The research in the field of Smart Cities and Italian banking foundations is still emerging and the definition and the conceptualisation of the role of these cities is still in progress.

Despite this situation, our research design concentrates on the evidence that firms, and in our case banking foundations, should operate and collaborate with public governments in order to further exploit the opportunities of smart cities (Scuotto et al., 2016).

This research represents a theoretical contribution in the field smart cities and banking foundations and, through a deductive approach, we analysed the reports on the strategic business plans of the Italian banking foundations of the period between 2017-2019, the corporate governance model and the internal organisation of such 
foundations in 2016, the notes to the financial statements, referring to 2015, and the websites in order to elaborate their general business model.

We analysed all the related documents published on the websites of ACRI (Associazione di Fondazioni e Casse di Risparmio Spa, 2014) and of the eighty-eight Italian banking foundations.

This study can be considered a multidisciplinary theoretical analysis because it combines theories regarding both smart cities and banking foundations in management studies.

This methodology gives evidence of an appropriate approach because there is limited research and theoretical knowledge on the role and related effects of foundations in the development of smart cities. A theoretical framework would contribute to future empirical research in the field and it differs from other studies because it emphasises assumption-challenging in the construction of research questions (Alvesson and Kärreman, 2007, 2011; Sandberg and Tsoukas, 2011).

In this case, the study aims at answering the following research questions:

- Research question 1: How do Italian banking foundations interact with smart cities?

- Research question 2: What is the impact of Italian banking foundations on the development of smart cities?

The case of Italian banking foundations is unique and it represents a virtuous model of interrelationships of public governments and the juridical institution of a banking foundation.

The business model of banking foundations represents the set of organisational and strategic solutions through which they acquire a competitive advantage. For smart city managers, as they are project managers, a better understanding of the potential benefits of having partners such as the banking foundations, should improve the decision-making process and the knowledge of specific processes and problems of the city. Therefore, this could be a chance for enhancing the setting of the city organisational objectives.

For researchers in the field of smart cities and business management, this paper points out several important aspects for future research.

\section{Discussion: the business model of Italian banking foundations}

Over the past few years, the impetus behind the process of smartening sustainable cities and improving smart cities has been to lay the foundation for a holistic approach to urban planning and development. This is further stimulating new research endeavours towards unlocking the potential of ICT of the new wave of computing for advancing urban sustainability and instigating urban projects in the same direction. The concept and development of smart sustainable cities has come to the fore as a promising response to the challenges and goals of sustainable development (Al-Nasrawi et al., 2015; Bibri and Krogstie, 2016; Höjer and Wangel, 2015) by developing smart and innovative solutions for improving sustainability, optimising efficiency of operations and services, and enhancing the quality of life.

There are several fields of activity which are described in literature in relation to the term Smart City: industry, education, participation, technical infrastructure, various 'soft factors'. But scholars have identified six characteristics as a roof for the further 
elaboration of smart cities which should incorporate the findings but also allow an inclusion of additional factors.

These are: smart economy, smart people, smart governance, smart mobility, smart environment and smart living.

Figure 1 Smart cities characteristics and factors

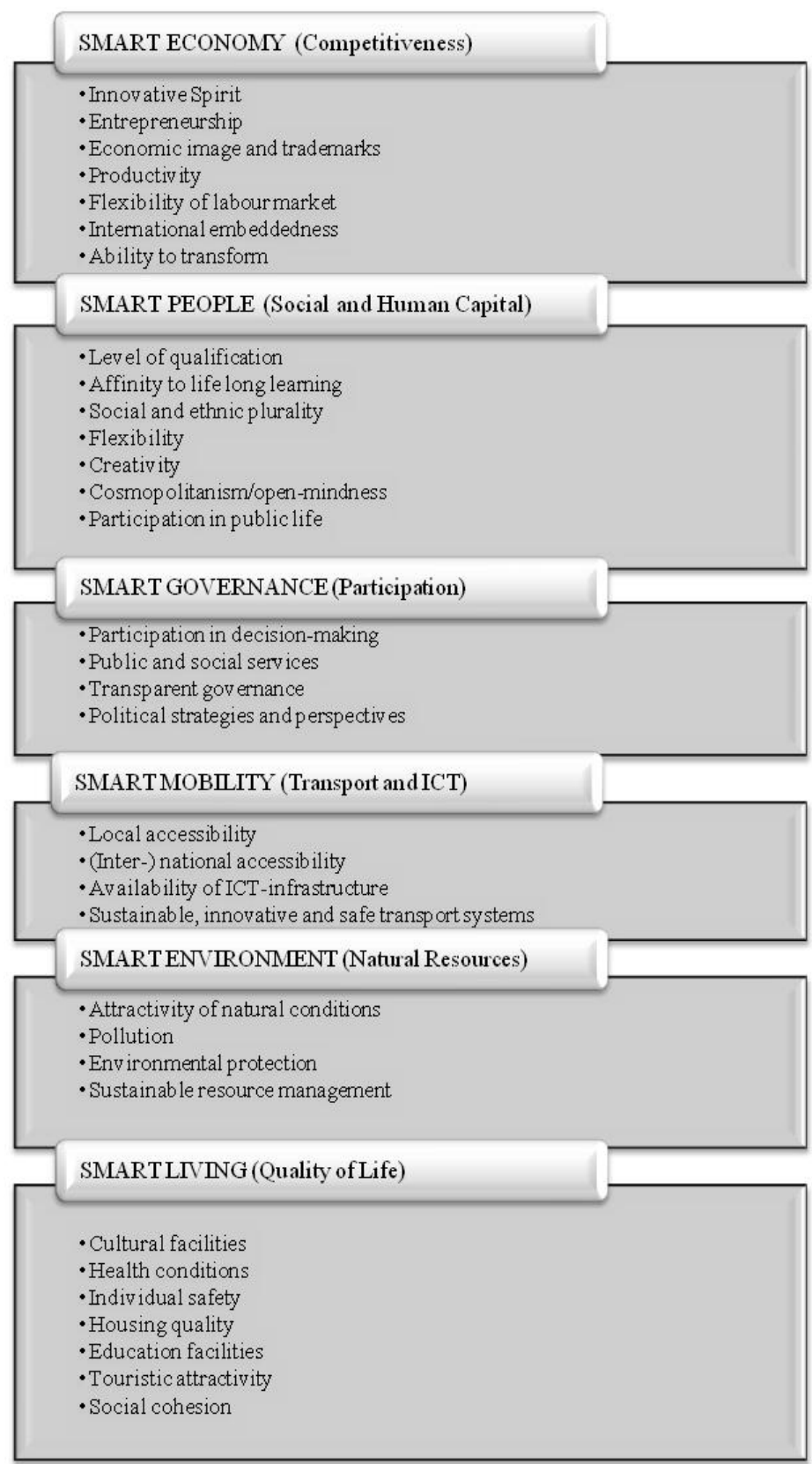

Source: Centre of Regional Science (2007) http://www.smartcities.eu 
The ranking of European medium-sized cities, elaborated by the Centre for Regional Science (2007), developed a transparent and easy hierarchic structure, where each level is described by the results of the level below. Each characteristic is therefore defined by a number of factors. Furthermore, each factor is described by a number of indicators.

By considering characteristics and factors of smart cities (Figure 1), we can better understand the business model of the eighty-eight Italian banking foundations and how their activities can positively impact on the development of those cities.

Banking foundations in Italy cover the primary role of promoting the development and the integration of Smart cities within their business.

The 88 reports on strategic business plans analysed and referring to the period between 2017-2019, the notes to the financial statements referring to 2015, the websites and the corporate governance composition highlight the new perspectives and objectives that the foundations aim at achieving.

The general business model of the Italian Banking Foundations (Figure 2) shows the critical success factors and the strategic guidelines followed by the governance and the internal control system of each foundation, and help answer RQ1.

The centre of the model represents the main objective of each foundation, which can be pursued thanks to the main activities carried out that we extrapolated by the reports on strategic business plans. The main objective can be achieved also thanks to the development of strategic guidelines, assets and success key-drivers that characterise each entity. But all activities and the value creation can be made possible only through a good management and governance, management of risks and internal controls.

Figure 2 General business model of Italian banking foundations (2017-2019) (see online version for colours)

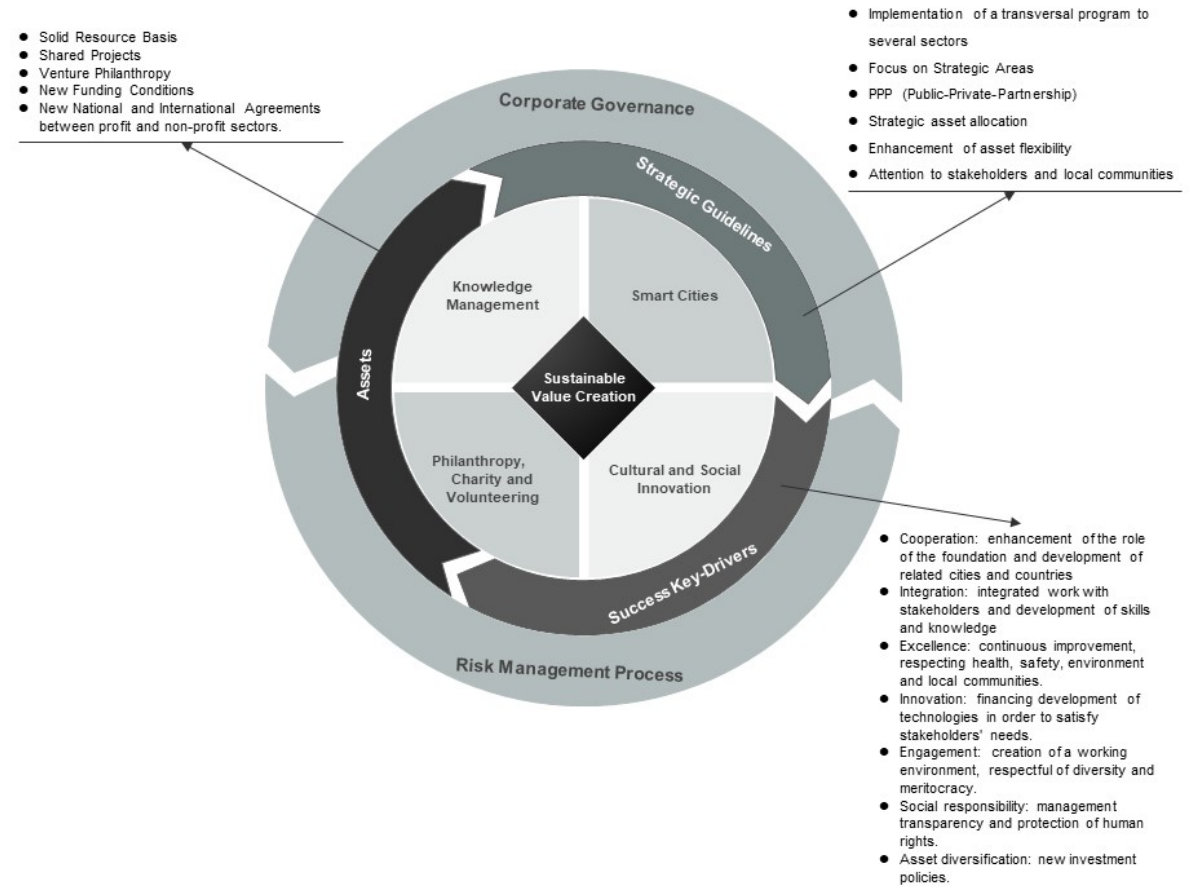

Source: Self-elaborated model 
All the elements of the model are described in Figure 2.

As mentioned in Figure 2, Italian banking foundations are legal subjects of private law, non-profit making, but with exclusive social aims. Therefore, their primary aim is to create sustainable value for the local community in which they operate, because they are attentive to stakeholders' needs.

To do that, they concentrate on four main areas: knowledge management, philanthropy, charity and volunteering, cultural and social innovation and smart cities.

As we can notice, smart cities represent one of the most important projects and strategic areas for these foundations. This is the way through which banking foundations interact with smart cities.

That means that their solid resource basis is also allocated in shared projects, like smart cities.

By following their strategic guidelines, banking foundations aim at implementing transversal programs to several sectors. This is the reason they cooperate with national and international profit and non-profit institutions in order to develop their success key drivers.

Asset flexibility, strategic asset allocation and venture philanthropy represent the drivers for the foundation success. Corporate governance boards, internal control system and in particular the risk management function have the main purpose to create sustainable value, by developing the success key-drivers, shown in Figure 2. The latter can represent the foundation mission.

Cooperation leads to the enhancement of the role of the foundation and development of cities and countries in which it operates. Integration means that the banking foundation works with stakeholders and, therefore, it tries to develop appropriate skills and knowledge to achieve its objectives and diversify investment policies. This element is linked to engagement, a driver that aims at leading the creation of a working environment, respectful of diversity and meritocracy.

Excellence instead involves continuous improvement, respecting health, safety, environment and local communities, which is linked to the social responsibility of each foundation, because management should be transparent and protect human rights.

Another important success key-driver is innovation, because the foundation, with new funding conditions tries to finance the development of technologies in order to satisfy stakeholders' needs.

Concluding, to answer RQ2, Italian banking foundations represent a virtuous institution in the development and transformation of Italian cities into smart and sustainable cities. By comparing the characteristics and factors of smart cities with the generalised business model of such foundations, it is evident the fundamental integration of the banking foundations into the development of smart cities. In fact, thanks to the investments and strategic guidelines, the Italian banking foundations economically and financially support public projects, such as the one of smart cities.

\section{Conclusions}

The present study focuses on the role of banking foundations in the Italian smart cities.

We first analysed the literature review on smart cities and on smart sustainable cities to provide the theoretical groundwork and give some definitions about the notion of 
'smart city' and 'smart sustainable city' because it was necessary for introducing the topic of banking foundations.

Italian banking foundations, as mentioned above, even though are legal subjects of private law, non-profit making, but with exclusive social aims, represent, in particular, businesses with the last institutional aim of satisfying the needs of the members of the local community. To this end, they set up a coordinated and unified system of economic operations that tend to regain the conditions for its own survival over time and to create value.

They represent the most interesting result of a privatisation reform in the field of nonprofit organisations in Italy.

Therefore, the purpose of the paper is to underline the opportunities and the potential benefits of banking foundations supporting the development of smart cities in Italy.

By analysing the reports on the strategic business plans of the period between 20172019 , the corporate governance model and the internal organisation of such foundations, the notes to the financial statements, referring to 2015, and the websites, we elaborated their general business model.

Italian banking foundations have the chance of knowing the city from the inside but also being aware of the surroundings and the system in which the city is located in. Therefore, thanks to their privileged position, they can support the growth and the transformation of the cities in which they are located into smart and smart sustainable cities. Their success key-drivers stress the importance of cooperation, integration, social responsibility and innovation.

This research, thanks to its multidisciplinary and deductive approach, contributes to the body of knowledge by providing a virtuous example of interactions and synergies between smart cities and banking foundations in Italy.

This methodology gives evidence of an appropriate approach because there is limited research and theoretical knowledge on the role and related effects of foundations in the development of smart cities.

The case of Italian banking foundations is unique and it represents a virtuous model of interrelationships of public governments and the juridical institution of a banking foundation.

The business model of banking foundations represents the set of organisational and strategic solutions through which they aim at acquiring competitive advantage. For smart city managers, as they are project managers, a better understanding of the potential benefits of having partners such as the banking foundations, should improve the decisionmaking process and the knowledge of specific processes and problems of the city. Therefore, this could be a chance for enhancing the setting of the city organisational objectives.

For researchers in the field of smart cities and business management, this paper points out several important aspects for future developments in this research field.

About the limits of this research, this work represents the first step of a far deeper analysis. Consequently, the theoretical framework represents the basis of future developments of core arguments deeply analysed in this context. 


\section{References}

Ahvenniemi, H., Huovila, A., Pinto-Seppä, I. and Airaksinen, M. (2017) 'What are the differences between sustainable and smart cities?', Cities, Vol. 60, No. 2017, pp.234-245.

Airoldi, G. (1995) Proprietà e governo delle aziende italiane, Egea, Milano.

Al Nuaimi, E., Al Neyadi, H., Nader, M. and Al-Jaroodi, J. (2015) 'Applications of bigdata to smart cities', Journal of Internet Services and Applications, Vol. 6, No. 25, pp.1-15.

Al-Nasrawi, S., Adams, C. and El-Zaart, A. (2015) 'A conceptual multidimensional model for assessing smart sustainable cities', Journal of Information Systems and Technology Management, Vol. 12, No. 3, pp.541-558.

Alvesson, M. and Kärreman, D. (2011) Qualitative Research and Theory Development, Mystery as Method. London: Sage.

Associazione di Fondazioni e Casse di Risparmio Spa (ACRI) (2014) Ventesimo rapporto sulle fondazioni bancarie, Roma [online] http://www.acri.it.

Bakici, T., Almirall, E. and Wareman, J. (2013) 'A smart city initiative: the case of Barcelona', Journal of the Knowledge Economy, Vol. 4, No. 2, pp.135-148.

Barbetta, G.P. (2008) 'Le Fondazoni di origine bancaria: dalla nascita per caso all'esercizio dell'innovazione sociale, in Turati, Piacenza e Segre (a cura di), Patrimoni \& Scopi', Per un'analisi economica delle fondazioni, Fondazione Giovanni Agnelli, Torino.

Bertini, U. (1990) Il sistema d'azienda. Schema di analisi., Studi di Economia e Politica Aziendale, Giappichelli, Torino.

Bibri, S.E. and Krogstie, J. (2016) 'On the social shaping dimensions of smart sustainable cities: A study in science, technology and society', Sustainable Cities and Society, forthcoming.

Bodega, D., Cioccarelli, G., Denicolai, S. and Vello, P.M. (2009) Fondazioni di origine bancaria: innovazione ed evoluzione, Franco Angeli, Milano.

Bompani, A. (2000) 'Le fondazioni bancarie', Profili organizzativi, civilistici, gestionali e di bilancio, Franco Angeli, Milano.

Borgonovi, E. (1993) 'La rilevanza del concetto di istituto per l'economia aziendale', in $A A . V V$., Scritti in onore di Carlo Masini, Vol. I, Egea, Milano.

Borzaga, C. and Cafaggi, F. (1999) Le fondazioni bancarie, Meridiana, Molfetta.

Brusa, L. et al. (2013) Lezioni di economia aziendale, Giappichelli, Torino.

Caragliu, A., Del Bo, C. and Nijkamp, P. (2009) 'Smart cities in Europe', in Serie research memoranda 0048, VU University Amsterdam, Faculty of Economics, Business Administration and Econometrics.

Carayannis, E.G. and Campbell, D.F. (2009) 'Mode 3 and quadruple helix: toward a 21st century fractal innovation ecosystem', International Journal of Technology Management, Vol. 46, Nos. 3-4, pp.201-234.

Carver, J. (2007) 'The promise of governance theory: beyond codes and best practices', Corporate Governance Review, Vol. 15, No. 6, pp.1030-1037.

Centre of Regional Science (2007) Smart Cities - Ranking of European Medium-Sized Cities [online] http://www.smartcities.eu (accessed on 2 November 2016).

Cerbioni, F. and Boesso, G. (2013) La governance delle fondazioni: leader al servizio della filantropia, McGraw-Hill, Milano.

Cioccarelli, G. and Previtali, P. (2002) Le fondazioni ex bancarie, Orientamento strategico, assetto organizzativo e competenze manageriali, Giuffrè, Milano.

Crociata, A. and Sacco, P.L. (2008) Fondazioni bancarie e sviluppo economico, Il Mulino, Bologna.

Decreto Legislativo 17 maggio (1999) n. 153, Disciplina civilistica e fiscale degli enti conferenti di cui all'art, 11, comma 1, del decreto legislativo 20 novembre 1990, $n$. 356, e disciplina fiscale delle operazioni di ristrutturazione bancaria, a norma dell'art. 1 della legge 23 Dicembre 1998, n. 4612, G.U. 31 maggio 1999. 
Del Giudice, M. (2016) 'Discovering the internet of things (IoT) within the business process management: a literature review on technological revitalization', Business Process Management Journal, Vol. 22, No. 2.

Donaldson, L. and Davis J.H. (1991) 'Stewardship theory or agency theory: CEO governance and shareholder returns', Australian Journal of Management, Vol. 16, No. 1, pp.49-65.

Fama, E.F. (1980) 'Agency problems and the theory of the firm', Journal of Political Economy, Vol. 88, No. 2, pp.288-307.

Fama, E.F. and Jensen, M.C. (1983) 'Separation of ownership and control', Journal of Law and Economics, Vol. 26, NO. 2, pp.301-325.

Ferraris, A. and Santoro, G. (2014) 'Come dovrebbero essere sviluppati i progetti di Social Innovations nelle Smart City? Un'analisi comparativa.', Impresa-Progetto Electronic Journal of Management, No. 4, pp.1-15.

Ferrero, G. (1968) Istituzioni di economia d'azienda, Giuffrè, Milano.

Ferrero, G. (1987) Impresa e Management, Giuffrè, Seconda Edizione, Milano.

Freeman, R.E. (1984) Strategic Management - A Stakeholder Approach, Pitman Publishing, Boston.

Gomez, P-Y. and Jones, B. (2000) 'Conventions: an interpretation of deep structures in organizations', Organization Science, Vol. 11, pp.696-708.

Gomez, P-Y. and Korine, H. (2005) 'Democracy and the evolution of corporate governance', Corporate Governance: An International Journal, Vol. 13, No. 6, pp.739-752.

Höjer, M. and Wangel, S. (2015) 'Smart sustainable cities: definition and challenges', in Hilty, L. and Aebischer, B. (Eds.): ICT Innovations for Sustainability, pp.333-349, Springer-verlag, Berlin.

Jensen M.C. and Meckling, W.H. (1976) 'Theory of the firm: managerial behaviour, agency costs and ownership structure', Journal of Financial Economics, Vol. 3, No. 4, pp.305-360.

Kilili, A. and Fokaides, P.A. (2015) 'European smart cities: the role of zero energy buildings', Sustainable Cities and Society, Vol. 15, No. 2015, pp.86-95.

Kramers, A., Höjer, M., Lövehagen, N. and Wangel, J. (2014) 'Smart sustainable cities: exploring ICT solutions for reduced energy use in cities', Environmental Modelling and Software, Vol. 56, pp.52-62.

Lazaroiu, G.C. and Roscia, M. (2012) 'Definition methodology for the smart cities model', Energy, Vol. 47, pp.326-332.

Legge 30 luglio (1990) n. 218 Disposizioni in materia di ristrutturazione e integrazione patrimoniale degli istituti di credito di diritto pubblico, G.U. 30 luglio 1990.

Lindhult, E., Campillo, J., Dahlquist, E. and Read, S. (2016) 'Innovation capabilities and challenges for energy smart development in medium sized European cities', Energy Procedia, Vol. 88, No. 2016, pp.205-211.

March, H. (2016) 'The smart city and other ICT-led techno-imaginaries: any room for dialogue with Degrowth?', Journal of Cleaner Production [online] http://dx.doi.org/10.1016/ j.jclepro.2016.09.154 (accessed 12 February 2017).

Marcon, G., Panozzo, F. and Marcon, C. (2002) Le Fondazioni bancarie del Nord-Est: forme di governo, scelte strategiche e modelli di gestione economico-finanziaria, Fondazione Cassa di Risparmio di Venezia.

Masini, C. (1978) Lavoro e risparmio, UTET, Torino.

Mattoni, B., Gugliermetti, F. and Bisegna, F. (2015) 'A multilevel method to assess and design the renovation and integration of Smart Cities', Sustainable Cities and Society, Vol. 15, pp.105-119.

Monge, F. (2016) Le fondazioni bancarie: cultura, valore, innovazione, Franco Angeli, Milano.

Navarro, J.L.A., Ruiz, V.R.L. and Nevado Peña, D. (2017) 'The effect of ICT use and capability on knowledge-based cities', Cities, Vol. 60, No. 2017, pp.272-280. 
Paroutis, S., Bennett, M. and Heracleous, L. (2014) 'A strategic view on smart city technology: the case of IBM smarter cities during a recession', Technological Forecasting and Social Change, Vol. 89, No. 2014, pp.262-272.

Pfeffer, J. and Salancik, G.R. (2003) The External Control of Organizations: A Resource Dependence Perspective, Stanford University Press, Stanford.

Piro, G., Cianci, I., Grieco, L.A., Boggia, G. and Camarda, P. (2014) 'Information centric services in smart cities', The Journal of Systems and Software, Vol. 88, pp.169-188.

Rivera, M.B., Eriksson, E. and Wangel, J. (2015) 'ICT practices in smart sustainable cities in the intersection of technological solutions and practices of everyday life', in 29th International Conference on Informatics for Environmental Protection (EnviroInfo 2015), Third International Conference on ICT for Sustainability (ICT4S2015), pp.317-324.

Sandberg, J. and Tsoukas, H. (2011) 'Grasping the logic of practice: theorizing through practical rationality', Academy of Management Review, Vol. 36, pp.338-360.

Sandulli, F.D., Ferraris, A. and Bresciani, S. (2016) 'How to select the right public partner in smart cities projects', R\&D Management, pp.1-14.

Schaffers, H., Komninos, N., Pallot, M., Trousse, B., Nilsson, M. and Oliveira, A. (2011) 'Smart cities and the future internet: towards cooperation frameworks for open innovation', The Future Internet Assembly, Springer Berlin Heidelberg, pp.431-446, DOI: 10.1007/978-3-64220898-0 31.

Scuotto, V., Ferraris, A. and Bresciani, S. (2016) 'Internet of things: applications and challenges in smart cities: a case study of IBM smart city projects', Business Process Management Journal, Vol. 22, No. 2, pp.357-367.

Sujata, J., Saksham, S., Tanvi, G. and Shreya, (2016) 'Developing smart cities: an integrated framework', Procedia Computer Science, Vol. 93, No. 2016, pp.902-909.

Tocqueville, A. de (2000) Democracy in America, Mansfield, H. and Winthrop, D. (Eds.) The University of Chicago Press, Chicago.

Toppeta, D. (2010) The Smart City Vision: How Innovation and ICT can Build Smart, Livable, Sustainable Cities, The Innovation Knowledge Foundation, [online] http://www.thinkinnovation.org/file/research/23/en/Toppeta Report 005 2010.pdf (accessed 2 February 2016).

Townsend, A. (2013) Smart Cities - Big Data, Civic Hackers and the Quest for a New Utopia, New York: Norton \& Company.

Ulrich, D. and Barney, J.B. (1984) 'Perspectives in organizations: resource dependence, efficiency, and population', Academy of Management Review, Vol. 9, pp.471-481.

Zappa, G. (1956) Le Produzioni nell'economia delle imprese, Giuffrè, Milano.

Zattoni, A. (2006) Assetti proprietari e corporate governance, Egea, Milano.

Zhuhadar, L., Thrasher, E., Marklin, S. and Ordóñez de Pablos, P. (2017) 'The next wave of innovation: review of smart cities intelligent operation systems', Computers in Human Behavior, Vol. 66, No. 2017, pp.273-281. 